This item was submitted to Loughborough's Research Repository by the author.

Items in Figshare are protected by copyright, with all rights reserved, unless otherwise indicated.

\title{
Residual relief separation: digital elevation model enhancement for geomorphological mapping
}

PLEASE CITE THE PUBLISHED VERSION

http://dx.doi.org/10.1002/esp.1659

PUBLISHER

(c) John Wiley \& Sons, Ltd.

VERSION

AM (Accepted Manuscript)

LICENCE

CC BY-NC-ND 4.0

\section{REPOSITORY RECORD}

Hillier, John K., and Mike J. Smith. 2019. "Residual Relief Separation: Digital Elevation Model Enhancement for Geomorphological Mapping”. figshare. https://hdl.handle.net/2134/13013. 
This item was submitted to Loughborough's Institutional Repository (https://dspace.lboro.ac.uk/) by the author and is made available under the following Creative Commons Licence conditions.

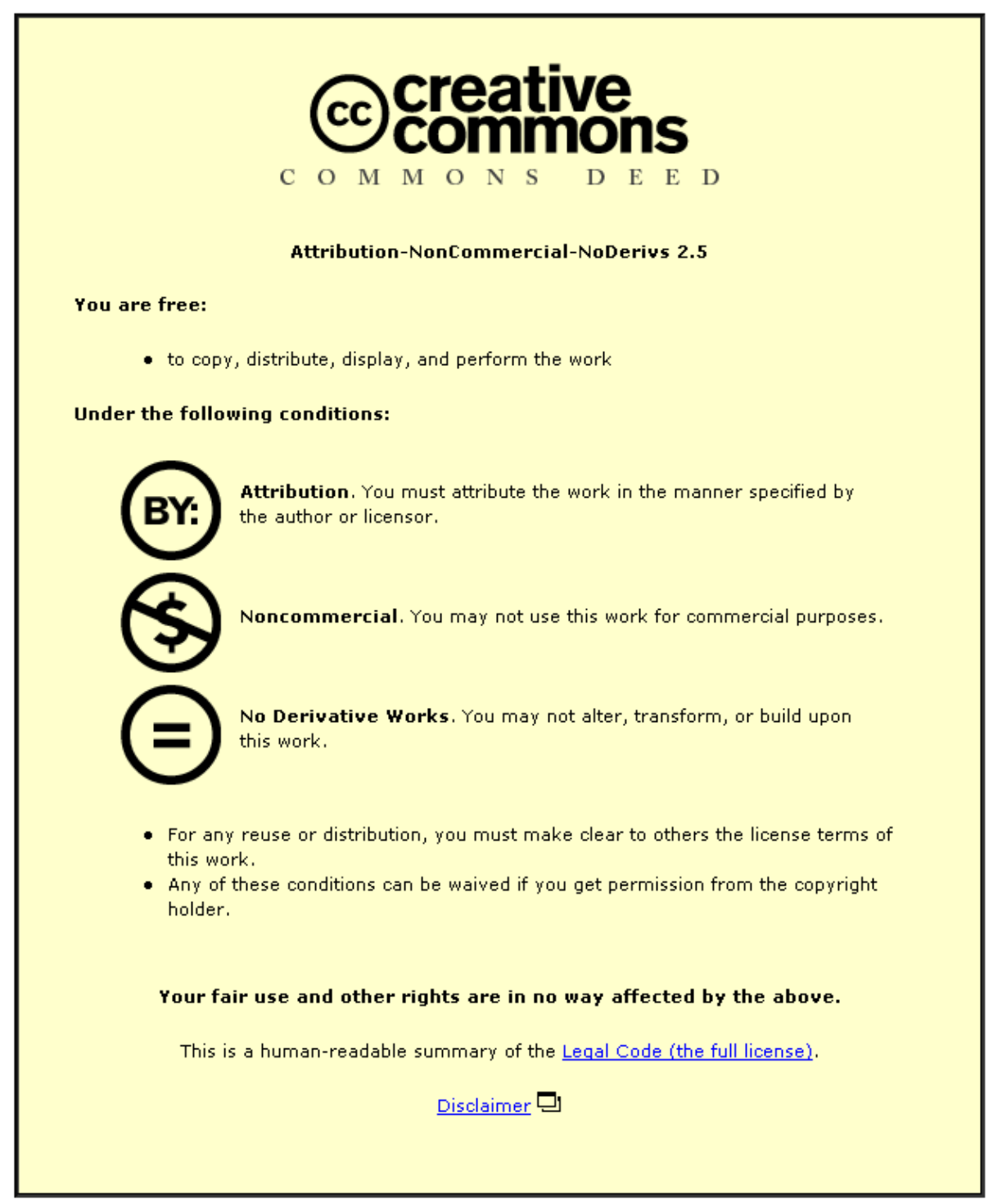

For the full text of this licence, please go to: http://creativecommons.org/licenses/by-nc-nd/2.5/ 


\title{
Residual Relief Separation: DEM Enhancement for Geomorphological Mapping
}

\section{J. K. Hiller ${ }^{1 *}$ and M. Smith ${ }^{2}$}

${ }^{1}$ Department of Earth Sciences, University of Cambridge, Downing Street, CB2 3EQ, UK; jkh34@cam.ac.uk

${ }^{2}$ School of Earth Sciences and Geography, Penrhyn Road, Kingston upon Thames, Surrey, KT1 2EE, UK; michael.smith@kingston.ac.uk

*Corresponding author: Tel. 00441223 764368; Fax. 00441223333450

\begin{abstract}
Geomorphologically mapped data form a primary set of observations that can be used to infer former environmental conditions. Thus, objective and consistent mapping of landforms from remotely sensed data (e.g. satellite imagery, digital elevation models (DEMs) is paramount for reconstructing palaeo-environments.
\end{abstract}

This paper proposes a technique, "residual relief separation", to enhance landforms in DEMs prior to visualization and digital mapping. This is applied to a $\sim 600 \mathrm{~km}^{2}$ region surrounding Lough Gara, Ireland, where drumlins ( $\sim 200 \mathrm{~m}$ wide) overlie a regional relief of hills ( $\sim 10 \mathrm{~km}$ wide). Here, residual relief separation uses this difference in width-scale. Regional relief is approximated by a $1 \mathrm{~km}$ wide median filter, then subtracted to leave the drumlins in a "residual" topography. In a second step, the residual relief is normalized to allow for amplitude variations in the drumlins across the area ( 5-40 $\mathrm{m}$ high). Finally, visualization uses a simple black-to-white colour scale for height.

Whilst not numerically out-performing other visualization techniques, this method performs equally well, and as the data are not "illuminated" there is no azimuthal bias. Additional benefits include the relatively simple calculation, intuitive visual comprehension, no emphasis of noise, and the possibility of using any desired visualization technique after the landscape has been topographically manipulated.

Key words: Drumlin, Lineament, Ireland, DEM, De-trend, Visualization 


\section{Introduction}

The occurrence and distribution of drumlins has long been of interest to glacial researchers (e.g., Close, 1867) and their interpretation remains a core methodology in understanding former glaciations. Drumlins are elongate hills typically several hundreds of metres to several kilometres long, ranging up to $50 \mathrm{~m}$ in height, that cover large expanses of areas that were formerly glaciated and are typified as a "basket of eggs" topography (Benn and Evans, 1998; Whittow, 2000). However this description fails to reflect a continuum of landforms (Rose, 1987) ranging from several metres (e.g., flutes) through to tens of kilometres (mega scale glacial lineations) in length. The descriptive term 'lineament' does not imply a process of formation and has been consistently used in literature regarding glacial landform mapping (e.g., Clark, 1997; Smith, 2005). This term will be used throughout the paper to refer to linear glacial landforms that have topographical expression at the land surface.

Lineaments are formed sub-glacially and can be classified as erosional (e.g., whalebacks), depositional or deformational landforms (e.g., Shaw, 1983; Boulton and Hindmarsh, 1987; Boulton, 1987; Benn and Evans, 1998; van der Meer et al, 2003). Evidence of the internal composition of drumlins has not been definitively interpreted, so the mechanism of their formation remains open to debate (e.g., Evans et al, 2006). Formation sub-glacially, with elongation parallel to ice flow, is generally agreed upon (e.g. Benn and Evans, 1998), facilitating interpretation of the behaviour of former ice cover.

Simple shape-related quantities, or "topological primatives", namely length, orientation and width (e.g. Mills, 1987) can be consistently calculated for lineaments. Kleman and Borgstrom (1996) and Clark (1997) provide methodological frameworks for the mapping and modelling of lineaments that have been employed in many other studies (e.g., Kleman et al, 1997; Stokes and Clark, 2003). When a variety of mapping styles and methods are assimilated, Clark et al (2004) urge "great care" in interpreting quantitative data, even number and length, as the results may not be directly comparable.

Landform mapping can be performed in the field (e.g., Wright, 1912), which is slow and not economically feasible for covering large regions (e.g., 1000s of $\mathrm{km}^{2}$ ). Remote sensing methodologies are therefore more suitable for regional analyses, with the use of aerial photography (e.g., Prest et al, 1967), satellite imagery (e.g. Punkari, 1982) and digital elevation models, or DEMs (e.g., Clark and Meehan, 2001), relatively common. Both satellite imagery and 
DEMs are available over large regions and are used by an operator to manually digitize, and thereby quantify, lineaments.

The interpretation of morphological evidence is key to understanding the formational environment of glacial landforms and subsequently inferring the behaviour of former ice sheets (Clark, 1997). Yet such inference remains a complex task where landform attributes (e.g., orientation) are used to infer the dynamics of palaeoenvironments. For example, the length-to-width ratio of lineaments has been suggested to reflect ice velocity (e.g., Stokes and Clark, 2002), strength of the sediments at the lineament core (e.g., Boulton and Hindmarsh, 1987), and length of formation period (e.g., Clark, 1993). Other parameters open for interpretation include spatial density, inter-lineament spacing, and along-length asymmetry (Mills, 1987).

Quantitative, internally consistent, mapping of lineaments may therefore yield considerable benefit. Lineaments, however, are commonly low 'amplitude' (with amplitude defined as the difference in relief between high points on the lineament and low areas to either side) and topographically subtle in comparison to the underlying hills. Figure $1 \mathrm{~b}$ is a grey scale image of elevation depicting low-amplitude lineaments (up to $\sim 40 \mathrm{~m}$ high) draped over higher amplitude hills $(\sim 200 \mathrm{~m})$. The lineaments remain difficult to identify as the range of grey scale shades used to visualise absolute elevation are dominated by the hills, which vary across larger horizontal distances and as such can be termed "regional relief" (e.g. Wessel, 1998).

In order to maximise the visibility of lineaments on DEMs, a range of standard image processing techniques (e.g., Clark, 1997; Smith and Clark, 2005) can be applied to manipulate the underlying data. No technique, however, satisfactorily produces a single image completely illustrating the glacial terrain (Smith and Clark, 2005). Even the most effective techniques suffer "azimuthal bias" (Smith and Clark, 2005) or produce images appearing little like the original topography.

To alleviate these problems, this paper proposes analysing glacial landscapes as topographies rather than as images. By applying mathematical operations to DEMs regional relief is quantified and then subtracted from the original terrain, leaving a "residual" relief that can be more easily visualized. Specifically, glacial lineaments are separated from the regional relief upon which they are superimposed. The following sections introduce the locality, data and lineament mapping procedure. Difficulties with visualization techniques are illustrated, and then the method based on residual relief separation is detailed and tested. 


\section{Locality, Data, and Mapping Method}

A study area was selected covering $600 \mathrm{~km}^{2}$ of terrain surrounding Lough Gara, County Roscommon, Ireland (Figure 1b). This region was glaciated during the Last Glacial Maximum and contains till draped across a bedrock ridge that is oriented NE to SW. An extensive suite of lineaments is formed in the till ranging from $100 \mathrm{~s} \mathrm{~m}$ to several $\mathrm{km}$ in length (Smith and Clark, 2005) and 5-40 $\mathrm{m}$ in amplitude. Lowest amplitudes are near the white cross (Figure 1b), the highest are NE of the white line, with the remainder $<20 \mathrm{~m}$ in amplitude. The study area $\left(\sim 53.94^{\circ} \mathrm{N}, 8.44^{\circ} \mathrm{W}\right)$ is relatively close to the modern coastline and forms a border with the Irish Midlands, a region that contains extensive suites of lineaments and ribbed moraine (Clark and Meehan, 2001). Clark and Meehan (2001) suggest that an ice dome was situated to the NW of the study area (County Donegal) and that, as peripheral to a mobile deglaciating ice core, the glacial geomorphology of the study area reflects a complex deglacial history. McCabe (1993) details the glacial context and provides a summary map of Irish glacial landforms.

The study area covers the same location that Smith and Clark (2005) used to compare different DEM visualisation techniques. The use of the same study area, data and observer (i.e. Smith) allows us to make direct comparisons. Figure 2 is the summary morphological map from Smith and Clark (2005) which represents a "control" dataset of all landforms resolvable to remotely sensed data. The reader is referred to Smith and Clark (2005) for published images of all the visualization techniques used.

The DEM was compiled by the Ordnance Survey of Ireland from contours produced using 1:40,000 stereoscopic aerial photography. Elevation data are stored as a regularised grid with a 50 $\mathrm{m}$ by $50 \mathrm{~m}$ pixel size using the Irish National Grid co-ordinate system. Heights are quoted to high precision (i.e. not rounded to the nearest $\mathrm{m}$ ). Smith and Clark (2005) note minor artefacts in the data. All processing was performed in Generic Mapping Tools (GMT; Wessel and Smith 1998), with subsequent digitizing completed using ERDAS Imagine 9.1.

After processing, optimal lineament identification and mapping was achieved through manual techniques (Clark, 1997). Lineaments (strong preferred orientation) are represented as simple lines and ovoid forms (little preferred orientation) as points. Re-mapping of lineaments suggests that interpreter consistency between mapping sessions is satisfactory (Smith and Clark, 2005). Qualitative visual agreement between sessions is strong, with localised inconsistencies. 


\section{Visualization Techniques}

Computer image processing techniques can be used to enhance the visual appearance of lineaments with respect to regional relief prior to mapping by an observer. Smith and Clark (2005) compared a variety of different methods for visualising DEMs, finding significant differences in mapping between 12 image-processing options; choice of technique is therefore important, however they also found no single technique was optimal. A key disadvantage they highlighted was "azimuthal bias", where a combination of visualisation technique (relief shading) and landform orientation can lead to significant errors in mapping. They also noted that, whilst some techniques are effective, their interpretation requires practise (e.g. gradient or curvature).

"Relief shading" of topography (e.g., Onorati et al, 1992; Pike, 1992) is notably simple and effective (Figure 3a). It uses simulated low-angle, oblique, illumination to visually enhance lineaments. A line along the length of the lineament, where down-slope direction changes rapidly, is highlighted, and is optimum if illuminated orthogonally to the principal lineament orientation. Lineaments remain less visible with relief shading from other azimuths (Lidmar-Bergstrom, 1991) and can therefore be enhanced or suppressed by manipulating the illumination direction (BonhamCarter, 1994). When quantitatively describing lineament populations, dependence of the mapping (e.g. orientation) upon illumination direction is termed "azimuthal bias" (Smith and Clark, 2005).

Some techniques can be used to visualise lineaments without incorporating azimuth. For instance, gradient (the magnitude of down-slope dip, the first derivative of elevation) is relatively large for lineaments and therefore a good diagnostic technique. In Figure $3 \mathrm{~b}$ small-amplitude (up to $\sim 40 \mathrm{~m}$ ) lineaments are emphasised over the larger amplitude $(\sim 200 \mathrm{~m})$ hills. As gradient images are not illuminated, there is no azimuthal bias, which is a major advantage. Gradient and curvature (second derivative of elevation) unfortunately also amplify noise and artefacts in the data. Artefacts from the conversion of the original contours, for example, are particularly prevalent in the SE corner of Figure $3 \mathrm{~b}$ such that lineaments are incompletely outlined. In addition, as intensity (or brightness) does not relate directly to elevation, these images can appear little like the original topography. Curvature (Figure 8a in Smith and Clark (2005)), for example, is high (dark shades) at breaks of slope near the top and bottom of lineaments, but low (light shades) on top and at midslope locations.

Both techniques above highlight lineaments through emphasising their steep sides relative to the underlying hills. Steep sides, however, are not the only characteristic differentiating lineaments 
from the regional relief. Respective width-scales are also different. The hills are $\sim 5-10 \mathrm{~km}$ wide, whilst the drumlins span a few $100 \mathrm{~m}$. Scale, therefore, can be used to ameliorate visualisation problems by substantially removing the regional relief to leave a "residual" topography dominantly comprised of the glacial landforms.

\section{Method}

The proposed method advocates processing a glacial landscape as a topography and involves two stages. The first stage, regional-residual separation, removes the regional relief, to leave the overlying lineaments. The second stage corrects for a variation in lineament amplitude across the area.

The first stage is methodologically similar to analyses of the ocean floor. Submarine topography, or bathymetry, contains various classes of seafloor features (e.g. submarine volcanoes, oceanic plateaus, and hot-spot swells). To examine a class of feature, therefore, it is common to use mathematical operations to isolate a component of bathymetry thought to best represent the class of feature of interest (e.g., McNutt, 1987; Smith, 1990; Hillier and Watts, 2004). For example Wessel (1998) separated the volcanic island of Hawaii ( 200 km wide) from the larger $\sim 1 \mathrm{~km}$ tall, $\sim 1000 \mathrm{~km}$ wide, topographic swell upon which it sits. Similarly, the different size-scales of lineaments and the regional relief can be used to facilitate a separation.

A $1 \mathrm{~km} \times 1 \mathrm{~km}$ sliding window (or kernel) that returns the median height to a central point (i.e., a median filter) is applied to the DEM (Figure 1b). The output in Figure 4a approximates the regional relief. Raster grid mathematics is then used to subtract these hills from the topography, leaving only lineaments and ovoid forms (Figure 4b), thereby "detrending" the landscape. Note that the $\pm 2 \mathrm{~m}$ scale used in Figure $4 \mathrm{~b}$ is similar to the lowest amplitude lineaments $(\sim 5 \mathrm{~m}$, near the white cross, Figure 4a) in the south, but saturates to black and white for the higher amplitude features in the north-east. Saturation means that elevations are compressed at the ends of the colour-scale and information about height variations within the lineaments is lost. This is particularly evident for the highest amplitude features ( $40 \mathrm{~m}$, near white circle, shown Figure $4 \mathrm{a})$.

The second stage is similar to a linear stretch used in remote sensing (e.g. Lillesand et al, 2004). This variant is adapted from Hillier et al, (2007) and corrects for the spatial changes in lineament amplitude in order to mitigate saturation problems, again using a kernel. Locally, upper and lower envelopes are evaluated around the lineament height data using a $1 \mathrm{~km} \times 1 \mathrm{~km}$ kernel, returning 
highest and lowest values respectively (i.e., minimum and maximum filters). Noise in the data produces steps in the envelopes, so a $0.5 \times 0.5 \mathrm{~km}$ mean filter is used to smooth the envelopes. A "relative height" between the envelopes is then calculated as:

$h_{\text {relative }}=\frac{\left(h-h_{\min }\right)}{\left(h_{\max }-h_{\min }\right)}$

where $h$ is elevation. This effectively normalizes height between the upper and lower bounds. Relative height is then displayed as a greyscale image in Figure 4c, which was used for all subsequent mapping.

Figure 5 illustrates the residual relief separation method along a profile that traverses the bedrock ridge and samples lineaments that decrease in amplitude from north to south, all whilst remaining perpendicular to the dominant lineament orientation. Figure 5a illustrates stage 1, where the regional relief (thick line) is subtracted from the landscape (thin line) to leave only lineaments (Figure 5b). Stage 2 involves normalising the amplitude of lineaments in the residual topography by stretching the relative relief (Figure 5b) to a common vertical amplitude (Figure 5c). A sample GMT script for performing the regional-residual separation and normalization is provided as supplementary material.

\section{Results}

Glacial landforms depicted in Figure 1 are clearly emphasised in Figure 4c with the benefit that there is no azimuth bias as with relief-shading (Figure 3a). Brightness in Figure 4c directly reflects amplitude of the lineaments and is therefore simple to visually interpret. Unlike Figure $4 \mathrm{~b}$, the colour scale does not saturate (i.e. become black and white only) for higher amplitude features in the north. Gradient (Figure 3b) also has amplitude-related display problems, becoming dark in the NE. Finally, digitized contours clearly visible in the SE corner of Figure $3 \mathrm{~b}$ are not greatly emphasised by the regional-residual separation and subsequent amplitude normalization. Overall, the residual relief method enhances the geomorphological signal-to-noise (i.e. lineamentto-regional relief) ratio of the data and displays lineaments clearly.

From digitization of Figure 4c, a generalised glacial geomorphological map of the Lough Gara region is presented in Figure 6. Summary statistics, quantitatively comparing the mapping performed using three DEM visualization techniques, are presented in Table 1. The analysis performed here identifies slightly fewer lineaments (340) and ovoid forms (84) than the control dataset (442 and 109 respectively), although the cumulative lengths are broadly comparable. Our 
visualization of the residual landscape also detects fewer lineaments and ovoid forms than orthogonal illumination, the best performing single visualization technique (Smith and Clark, 2005).

Qualitative assessment of Figure 6 shows good agreement between mapping of the separated and normalized residual relief and the control dataset, but with some localised differences. These are illustrated on Figure 6 where some ovoid forms are interpreted as lineaments (1), and some lineaments as multiple lineaments $(2,3)$. There are also ovoid forms in the control dataset that were not identified in the present mapping although high residual relief (grey shades) indicates landforms there $(4,5)$. Further elongate landforms (grey shades) are not identified in either the control dataset or mapping of the separated residual relief (6). Subjectivity, therefore, explains some of the variation shown Table 1. However, identifying lineaments retrospectively is more straightforward than interpretation from an unmarked image.

\section{Discussion}

In order to map subtle glacial morphologies such as lineaments, this paper has introduced residual relief separation as a technique to emphasise them over higher amplitude, regional relief, features. The technique uses width-scale as the principal discriminator between "narrow" lineaments and "wide" regional topography. This form of analysis has several advantages. Separated and normalized residual relief is comparatively simple to calculate and, as it directly reflects topography of the selected class of landform, remains intuitive to visually comprehend. It is also independent of pixel size, robust to significant noise in the data and highlights data artefacts less than surface derivatives. As it is not illuminated there is no "azimuthal bias".

However, it is disappointing that the technique identified fewer lineaments than both the control dataset and orthogonal illumination, although cumulative lineament length is comparable. It is possible that the level of measurement noise in the data is reached before improvements to the geomorphological signal strength have had a significant effect. Alternatively, false positives in the illumination mapping, or other factors associated with manual interpretation, may explain the variability. Given these considerations we feel able to argue that analysis based on residual relief separation performs similarly well to the best of other techniques reviewed by Smith and Clark (2005). 
It may be possible to improve the geomorphological signal-to-noise (i.e. lineament-to-regional relief) ratio for subtle topographic forms through the use of higher spatial resolution DEM data, particularly as the study area is largely unaffected by "surface clutter" (e.g. forests, buildings). Areas dominated by "surface clutter" are far more complex to map geomorphologically, with all the visualization techniques requiring careful scrutiny. For example, gradient imagery will outline features such as walls, hedges, forest stands and buildings. Indeed it can be used as part of a processing chain for the removal of surface features (e.g. Alharthy and Bethel, 2002). A residual relief separated by the method in this paper in a cluttered landscape would include all features at $a$ similar width scale to the landforms being studied.

More generally, the principle of using width-scales to separate classes of morphological features of interest to earth scientists is established. Residual relief separation improves the signal-to-noise ratio of a landscape and can be visualized directly or have subsequent processing applied. Note that any filter can be used to perform the regional-residual separation (e.g. mean, median, mode) and can be combined with a variety of different normalization techniques (e.g. linear contrast stretch, histogram equalisation). Given this variety it is desirable to identify 'optimal' regionalresidual separators where the best filter parameters are ascertained with respect to numerical criteria (e.g. Wessel, 1998). "Optimal", and the method by which it is determined, will depend upon the regional relief, landforms being mapped and source DEM.

A truly 'objective' method would use quantitative, and therefore exactly reproducible, measures to parameterize and directly detect lineaments on DEMs: perhaps assigning a threshold break-ofslope (i.e. curvature) around them. Ideally an automated lineament-detection algorithm would be used to perform such objective mapping, increasing the rates of detection and reducing errors of omission and commission. This, however, remains a difficult task for landforms such as drumlins where there is a wide range in amplitude and length, coupled with a highly variable plan form shape related to the modification of landforms during multiple ice flow events. In such an environment, manual mapping remains the optimum technique.

\section{Conclusions}

Manually mapping and quantifying glacial landforms is important as the first step in understanding the extent and dynamics of former ice cover. Visualization techniques aim to assist mapping by enhancing the appearance of selected landforms. This research demonstrates the use of width-scale parameters to enhance landscape visualization. Specific conclusions are:- 
- Separating landforms of specific width-scales into a residual component of relief can be achieved using localised statistical operations (i.e. sliding windows or kernels) applied to a DEM. This "residual relief separation" emphasises landforms allowing them to be subsequently better visualized.

- Normalizing the amplitude of the residual relief can remove spatial variations in landform amplitude, thereby allowing them to be better visualized on the same image.

- Together, the above operations significantly increase the signal-to-noise (e.g. lineament-tohill) ratio of elevation data so that when displayed using a simple greyscale image glacial lineaments are easily identified. Specifically, in identifying lineaments, the method performs similarly well to the best of other techniques reviewed by Smith and Clark (2005).

- Benefits of an approach based on residual separation include independence from pixel size, robustness to noise in the data, low significance of data artefacts, an output directly reflecting the selected class of landform, independence from azimuthal bias, and the potential to apply any standard visualization technique to the normalized residual topography containing lineaments.

- More generally, the principle of using width-scales to separate classes by means of morphological features of interest to earth scientists is established.

\section{Acknowledgements}

We thank Professor J. Rose and an anonymous reviewer whose comments greatly improved the quality of the manuscript. JKH is funded by St Catharine's College, Cambridge. 
Figure 1 - a) Location map of the study area surrounding Lough Gara, Ireland, modified from Smith and Clark (2005). b) Greyscale visualisation of DEM data for the study area. Black and white dashed line indicates the profile in Fig. 5. White markings indicate lineament amplitude; lowest amplitudes $(\sim 5 \mathrm{~m})$ near the cross, highest $(\sim 40 \mathrm{~m})$ near the circle, generally high $(>20 \mathrm{~m})$ are NE of the line whilst those SW of it are generally $<20 \mathrm{~m}$ high. Copyright permit MP 001904 (Ordnance Survey of Ireland).

Figure 2 - (a) Morphological map of all resolvable landforms in the Lough Gara area, Ireland., produced by break-of-slope mapping from DEMs relief-shaded with an illumination azimuth of $20^{\circ}$ and $290^{\circ}$. (b) Generalized lineament map derived from the morphological map (after Smith and Clark, 2005).

Figure 3 - Examples of visualization techniques applied to elevation data. a) Relief shading, with illumination from $020^{\circ}$, orthogonal to the dominant lineament orientation (Smith and Clark, 2005). b) Down-dip magnitude of topographic slope or gradient. High gradients are black, whilst horizontal planes are white. (i) highlights a region where contour artefacts are readily noticeable. Copyright permit MP 001904 (Ordnance Survey of Ireland).

Figure 4 - Processing of topography in Fig. 1. Large scale ( $\sim 5-10 \mathrm{~km}$ wide $)$ hills in a) are approximated by a $1 \mathrm{~km} \times 1 \mathrm{~km}$ sliding window that returns the median height to a central point (i.e. median filter). White markings indicating lineament amplitudes (as per Fig. 1). Subtracting the hills from the topography leaves the lineaments in b). c) plots relative elevation, which corrects for the spatially variable amplitude of the lineaments.

Figure 5 - Illustration of residual relief separation processing (see Fig. 1 for profile location). a) Regional relief (thick line), overlain by lineaments (thin line). b) Lineament component of terrain after the removal of regional relief. The envelope (grey shade) shows the upper and lower bounds (including off-profile effects). c) Contrast is increased through normalization.

Figure 6 - Comparison between lineaments mapped from the image of the normalized and separated residual relief (dark-grey lines) and the "control" observations (thin black lines; see text). Filled circles are ovoid forms (similarly dark grey and black). The $100 \mathrm{~m}$ topographic contour depicts the location of hills, with the prominent NE-SW ridge a thick black line. Light grey areas have relative heights of $>0.6$. Numbered ovals are discussed in the text. 


\section{References}

Alharthy, A. and Bethel, J., 2002. Heuristic filtering and 3D feature extraction from LiDAR data. In Proceedings of the International Society for Photogrammetry and Remote Sensing, Vol. XXXIV, part 3, A29.

Benn, D. and Evans, D., 1998. Glaciers and Glaciation. Arnold, London.

Bonham-Carter, G.F., 1994. GIS for Geoscientists. Elsevier Science, Oxford.

Boulton, G.S., 1987. A theory of drumlin formation by sub-glacial sediment deformation. In: J. Menzies and J. Rose (Editors), Drumlin Symposium. Balkema, Rotterdam.

Boulton, G.S. and Hindmarsh, R.C.A., 1987. Sediment deformation beneath glaciers: rheology and geological consequences. Journal of Geophysical Research, 92, 9059-9082.

Clark, C.D., 1993. Mega-scale glacial lineations and cross-cutting ice-flow landforms. Earth Surface Processes and Landforms, 18: 1-29.

Clark, C.D., 1997. Reconstructing the evolutionary dynamics of palaeo-ice sheets using multitemporal evidence, remote sensing and GIS. Quaternary Science Reviews, 16(9): 1067-1092.

Clark, C.D. and Meehan, R.T., 2001. Subglacial bedform geomorphology of the Irish Ice Sheet reveals major configuration changes during growth and decay. Journal of Quaternary Science, 16(5): 483-496.

Clark, C.D, Evans, D.J.A., Khatwa, A., Bradwell, T., Jordan, C.J., Marsh, S.H., Mitchell, W.A. and Bateman, M.D., 2004. Map and GIS database of glacial landforms and features related to the last British Ice Sheet. Boreas, 33: 359-375.

Close, M.H., 1867. Notes on the general glaciation of Ireland. Journal of the Royal Geographical Society of London, 1: 207-242.

Evans, D.J.A., Rea, B.R., Hiemstra, J.F. and O'Cofaigh, C., 2006. A critical assessment of subglacial mega-floods: a case study of glacial sediments and landforms in south-central Alberta, Canada. Quaternary Science Reviews, 25: 1638-1667.

Hillier, J.K., Bunbury, J. and Graham, A., 2007. Monuments on a migrating Nile. Journal of Archaeological Science, 34: 1011-1015. doi:10.1016/j.jas.2006.09.011.

Hillier, J. K. and Watts, A. B., 2004. Plate-like subsidence of the East Pacific Rise - South Pacific Superswell system. Journal of Geophysical Research 109. doi:10.1029/2004JB003041.

Kleman, J. and Borgström, I., 1996. Reconstruction of palaeo-ice sheets: the use of geomorphological data. Earth Surface Processes and Landforms, 21: 893-909.

Kleman, J., Hätterstrand, C., Borgström, I. and Stroeven, A., 1997. Fennoscandian palaeoglaciology reconstructed using a glacial geological inversion model. Journal of Glaciology, 43(144): 283-299.

Lidmar-Bergström, K., Elvhage, C. and Ringberg, B., 1991. Landforms in Skane, south Sweden. Geografiska Annaler, 73A: 61-91. 
Lillesand, T.M., Kiefer, R.W. and Chipman, J.W., 2007. Remote sensing and image interpretation (Sixth Edition). John Wiley and Sons, New York.

McCabe, A.M., 1993. Drumlin bedforms and related ice-marginal depositional systems in Ireland. Irish Geography, 26(1): 22-44.

McNutt, M.K. and Fischer, K.M., 1987. The South Pacific Superswell. In: Keating, B.H., Fryer, P., Batiza, R. and Boehlert, G.W. (Editors), Geophysical Monograph 43. American Geophysical Union, Washington DC, pp25-34.

Mills, H.H., 1987. Morphometry of drumlins in the northeastern and north-central USA. In: J. Menzies and J. Rose (Editors), Drumlin Symposium. Balkema, Rotterdam, pp. 131-147.

Onorati, G., Poscolieri, M., Ventura, R., Chiarini, V. and Crucilla, U., 1992. The digital elevation model of Italy for geomorphology and structural geology. Catena, 19: 147-178.

Pike, R.J., 1992. Machine visualisation of synoptic topography by digital image processing. U.S. Geological Survey Bulletin, 2016.

Prest, V.K., Grant, D.R. and Rampton, V.N., 1968. The Glacial Map of Canada. Geological Survey of Canada.

Punkari, M., 1982. Glacial geomorphology and dynamics in the eastern parts of the Baltic Shield interpreted using Landsat imagery. Photogrammetric Journal Finland, 9: 77-93.

Rose, J., 1987. Drumlins as part of a glacier bedform continuum. In: J. Menzies and J. Rose (Editors), Drumlin Symposium. Balkema, Rotterdam, pp. 103-116.

Shaw, J., 1983. Drumlin formation related to inverted melt-water erosional marks. Journal of Glaciology, 29(103): 461-479.

Smith, M.J. and Clark, C.D., 2005. Methods for the visualisation of digital elevation models for landform mapping. Earth Surface Processes and Landforms, 30(7): 885-900.

Smith, W. H. F., 1990. Marine geophysical studies of seamounts in the Pacific Ocean Basin. PhD thesis, Columbia Univ. 216 pp.

Stokes, C.R. and Clark, C.D., 2002. Are long subglacial bedforms indicative of fast ice flow? Boreas, 31: 239-249.

Stokes, C.R. and Clark, C.D., 2003. The Dubawnt Lake palaeo-ice stream: evidence for dynamic ice sheet behaviour on the Canadian Shield and insights regarding the controls on ice-stream location and vigour. Boreas, 32: 263-279.

van der Meer, J.J.M., Menzies, J., Rose, J. 2003. Subglacial till: the deformable glacier bed. Quaternary Science Reviews, 22, 1659-1685.

Wessel, P., 1998. An empirical method for optimal robust regional-residual separation of geophysical data. Mathematical Geology, 30: 391-408.

Wessel, P. and Smith, W.H.F., 1998. New, improved version of Generic Mapping Tools released. Eos Transactions of the American Geophysical Union, 79: 579.

Whittow, J., 2000. Dictionary of Physical Geography. Penguin, London. 


\begin{tabular}{|l|l|l|l|}
\hline Method & Lineaments & Ovoid Forms & $\begin{array}{l}\text { Cumulative } \\
\text { Length } \\
(\mathbf{k m})\end{array}$ \\
\hline Control $^{1}$ & 442 & 109 & 263 \\
\hline $\begin{array}{l}\text { Orthogonal } \\
\text { Illumination }^{1}\end{array}$ & 371 & 101 & 289 \\
\hline Our Analysis & 340 & 84 & 271 \\
\hline
\end{tabular}

Table 1 - Mapped features. ${ }^{1}$ from Smith and Clark (2005) 

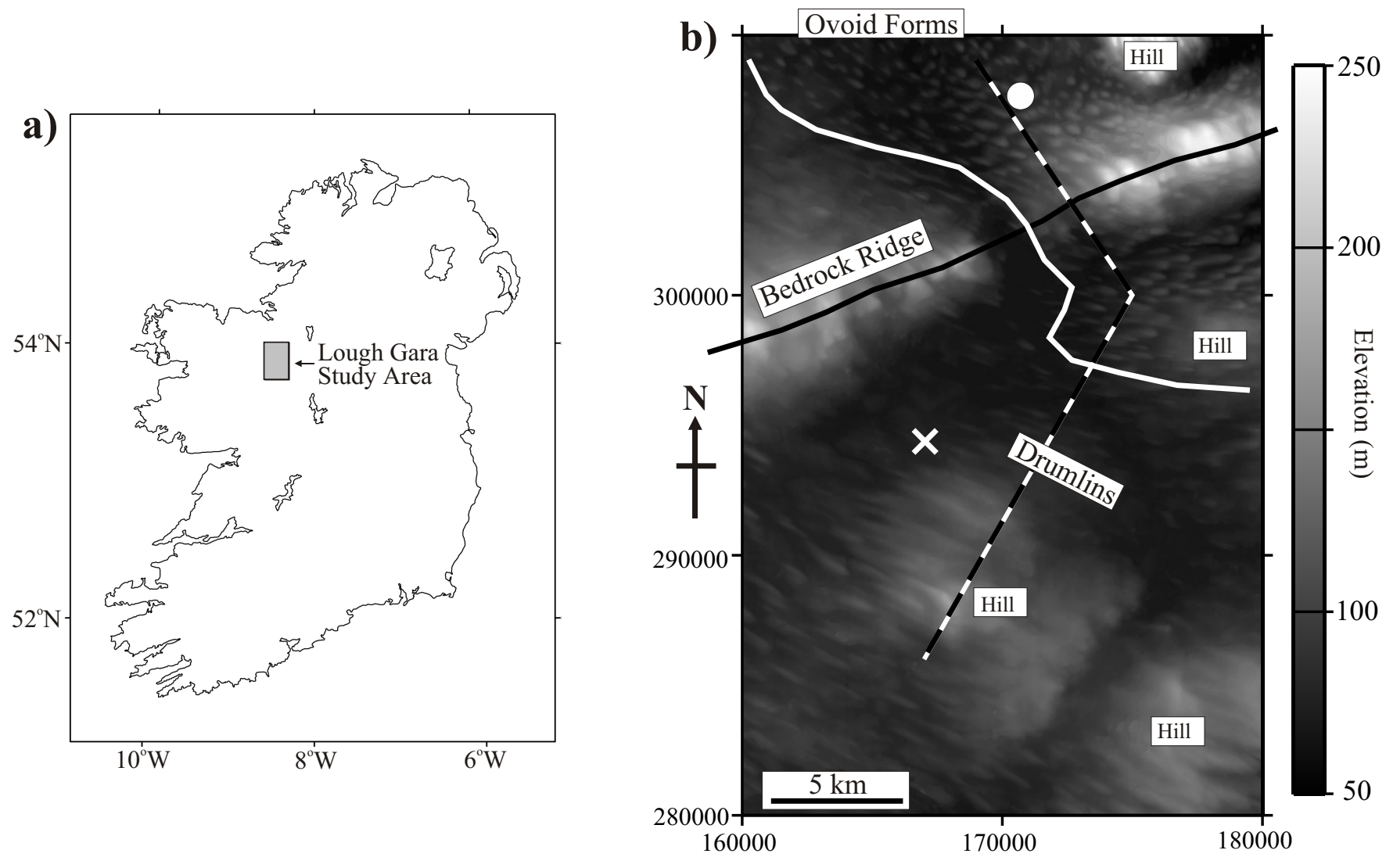

Figure 1
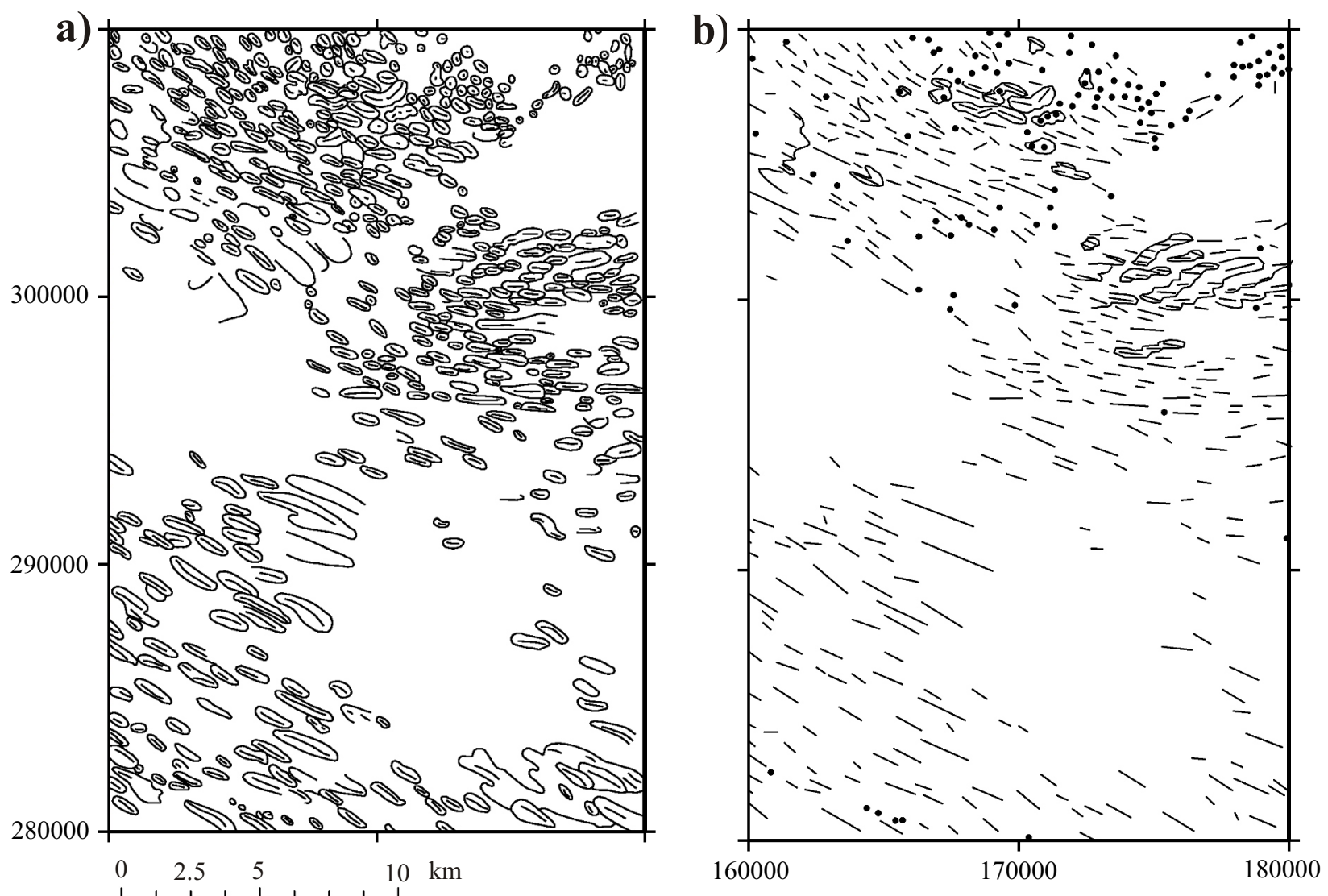

Figure 2 
a)

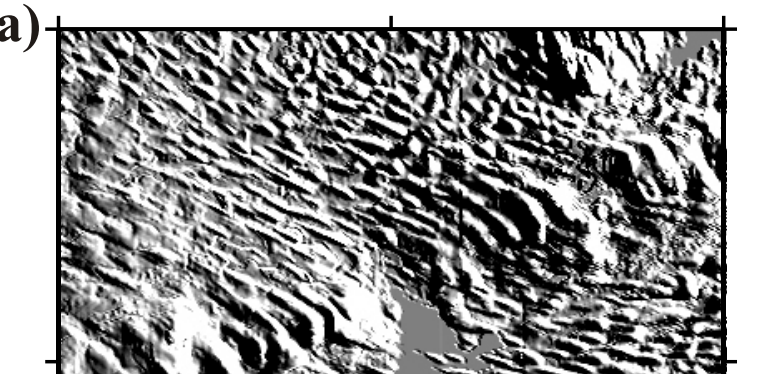

24. 190

Wh

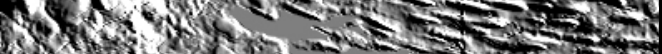

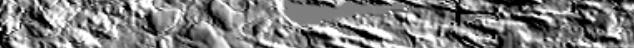

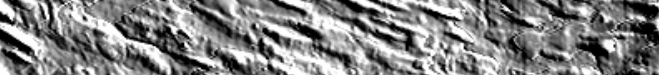

- If

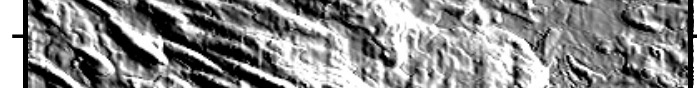

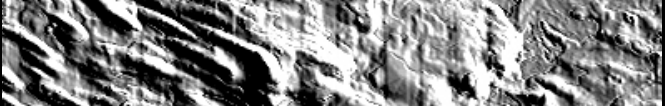

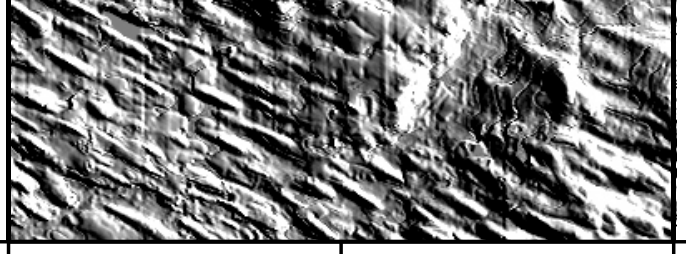

160000

170000

180000

280000

290000

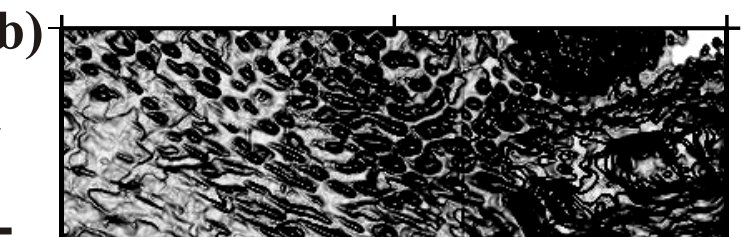

300000

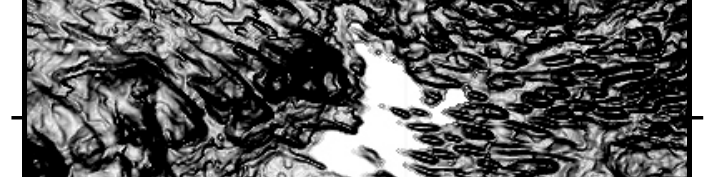

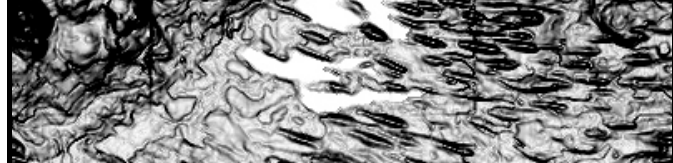

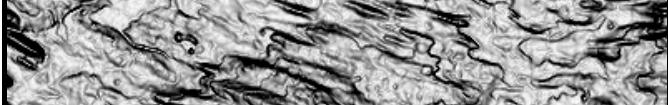

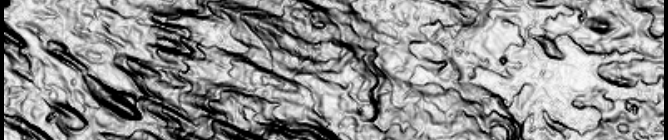

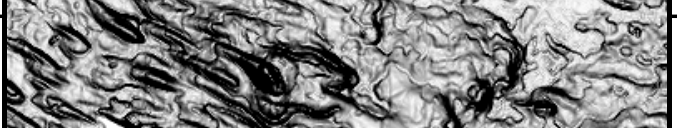

$\rightarrow$ Cn $\rightarrow$.

S. 1 - 25

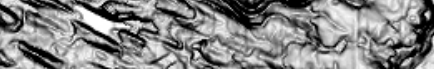

40 .

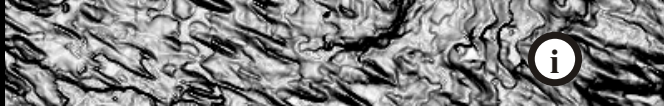

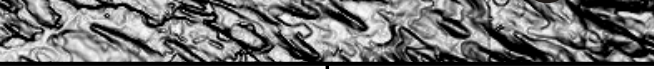

160000

170000

180000

Figure 3 

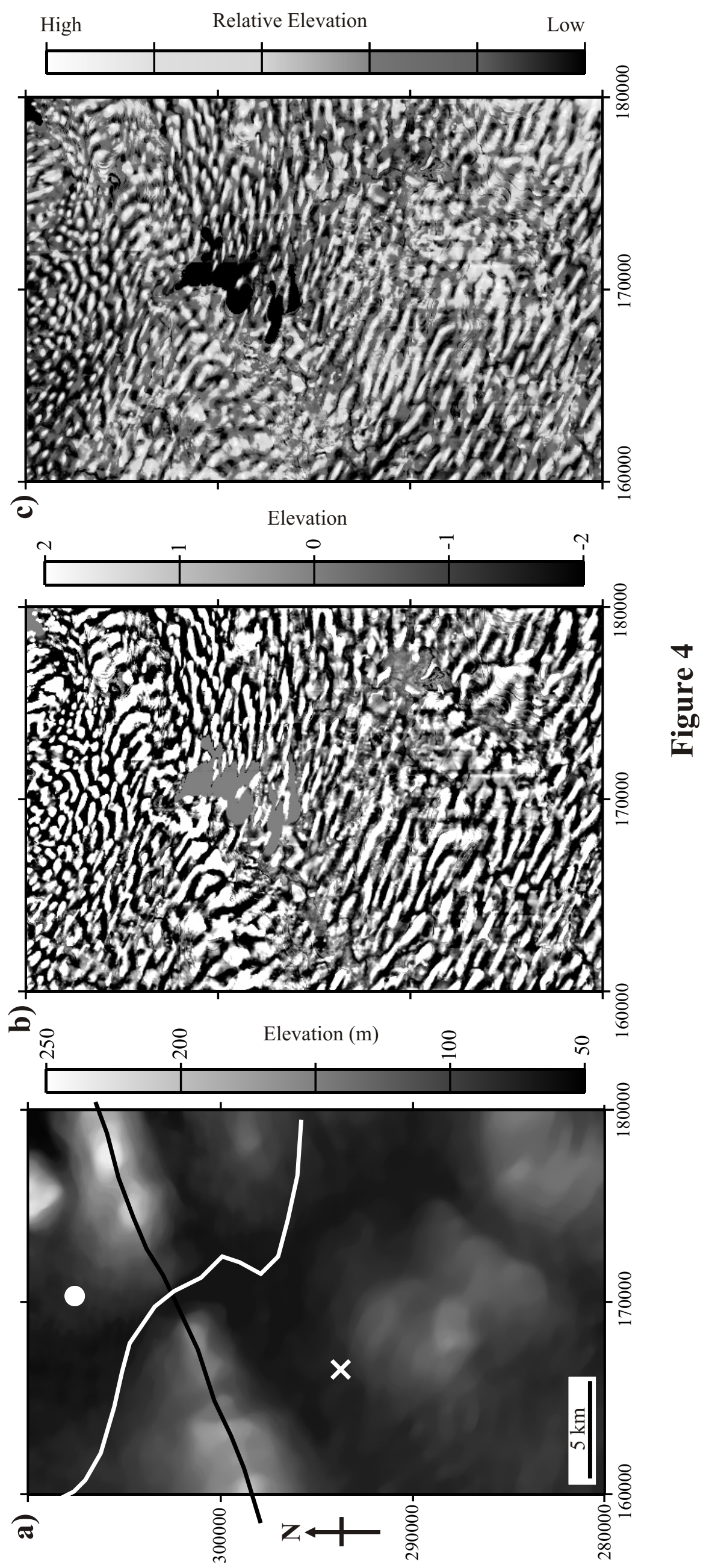

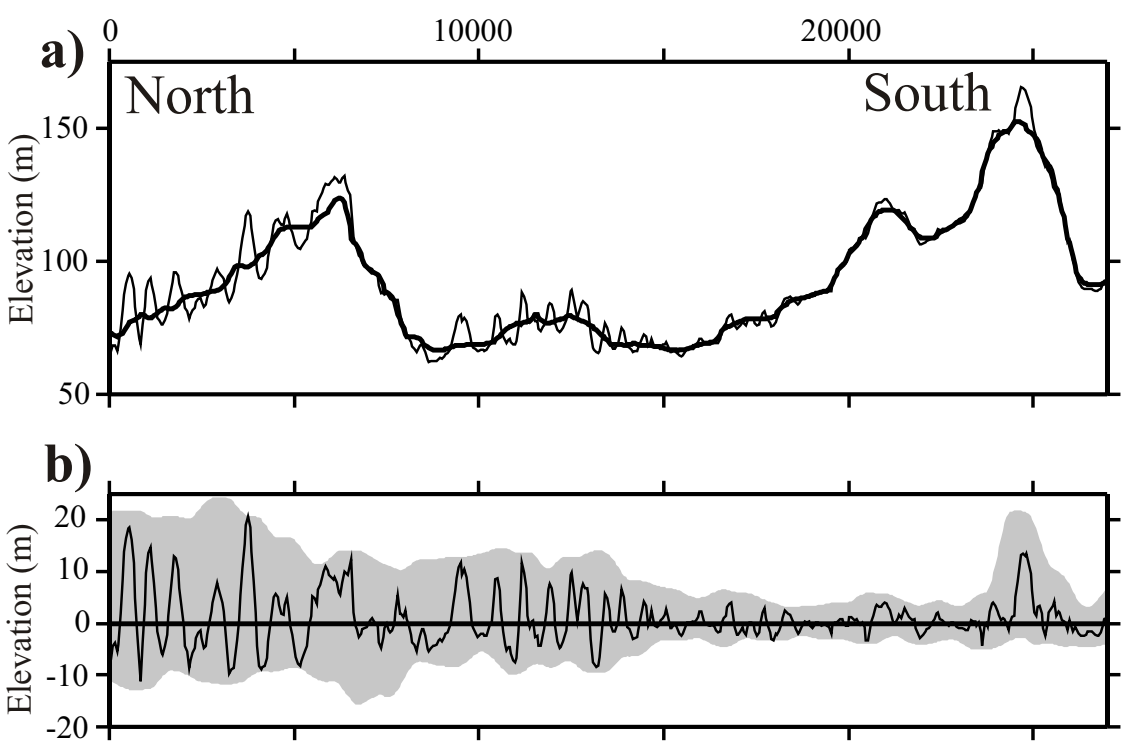

Figure 5
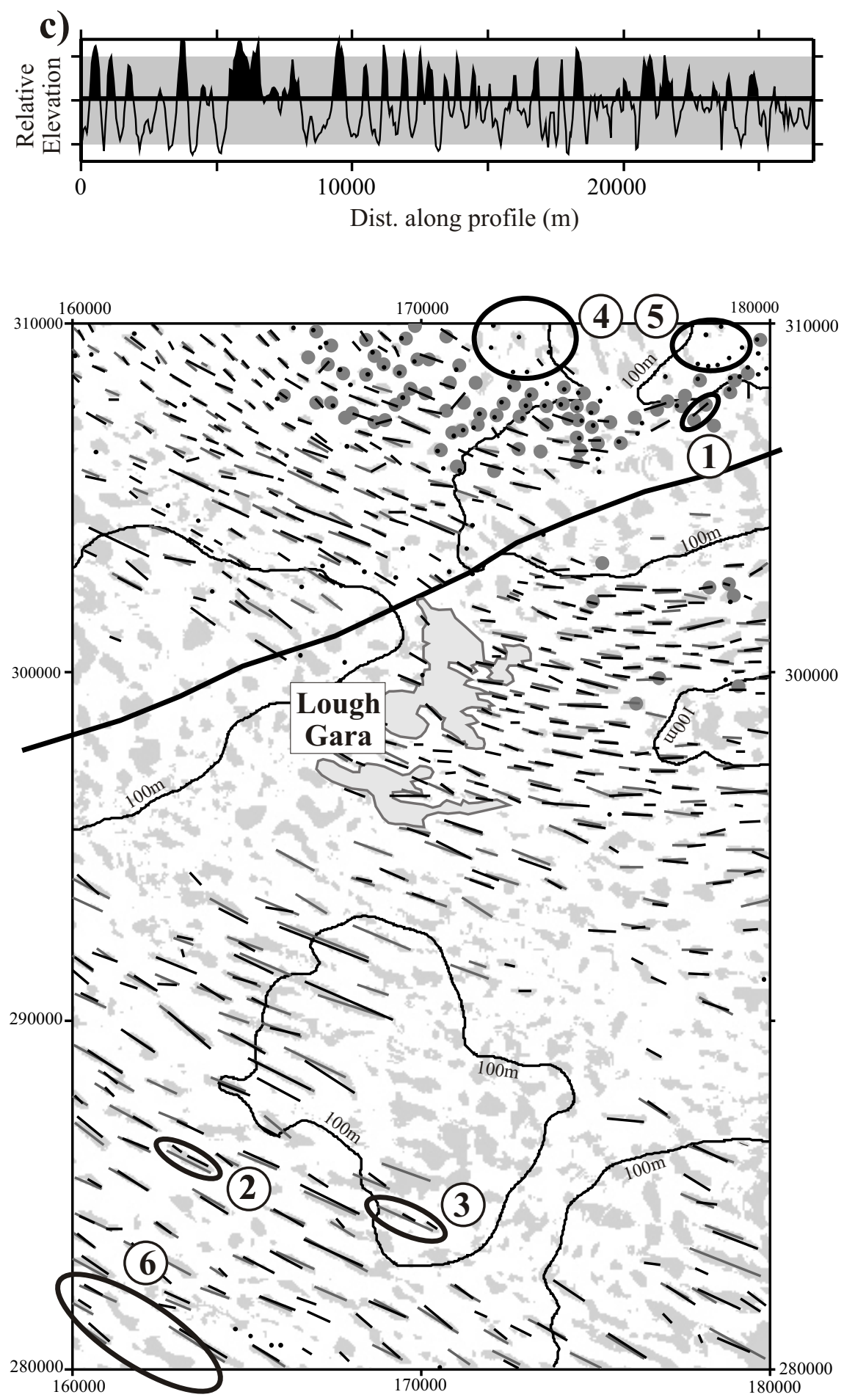

Figure 6 